\title{
Türkiye’de Banka Kredi Kanalının Etkinliği
}

\section{The Effectiveness of Bank Credit Channel in Turkey}

\author{
Dr. Öğr. Üyesi Nazan ŞAHBAZ KILINÇ (iD) ${ }^{1}$, Dr. Öğr. Üyesi Efe Can KILINÇ (iD)
}

\section{Öz}

Parasal otoritenin yürütmüş olduğu para politikası, reel ekonomiyi; geleneksel faiz kanalı, varlık fiyatları kanalı, döviz kuru kanalı, kredi kanalı ve beklenti kanalı olmak üzere parasal aktarım kanalları aracılığıyla etkilemektedir. Bu çalışmanın esas konusunu oluşturan kredi kanalı, banka kredileri kanalı ve bilanço kanalı olarak iki alt kanala ayrılmaktadır. Bu çalışmanın amacı, 2003Ç1-2018Ç4 döneminde Türkiye'de banka kredi kanalının etkinliğinin VAR modeli kullanılarak araştııılmasıdır. Analizde para politikası göstergesi olarak kısa vadeli faiz oranları kullanılmış ve faiz oranındaki değişikliklerin özel sektörün (finansal olmayan) kredi hacmine olan etkileri araştırılmıştır. Etki-tepki fonksiyonlarının sonuçları Türkiye'de banka kredi kanalı mekanizmasının çalıştığını göstermiştir.

Anahtar Kelimeler: Parasal aktarım mekanizması, banka kredi kanalı, VAR modeli

Makale Türü: Araştırma

\begin{abstract}
Monetary policy carried out by a monetary authority affects real economy by means of monetary transmission channels consisting of traditional interest rate channel, asset pricing channel, exchange rate channel, credit channel, and expectation channel. Credit channel forming the main subject of this study is divided into two subclasses: Bank Credit Channel and Balance Sheet Channel. The objective of this study is to analyze the effectiveness of bank credit channel for Turkey for the period of 2003Q1-2018Q4 by using Vector Autoregressive Model. In the analysis, short-term interes rate is considered as indicator of monetary policy and impact of changes in policy rate on private non-financial sector credit volume were investigated. The result of impulse-response functions revealed that bank credit channel mechanism works in Turkey.
\end{abstract}

Keywords: Monetary transmission mechanism, bank credit channel, VAR model

Paper Type: Research

${ }^{1}$ Kırıkkale Üniversitesi, İktisadi ve İdari Bilimler Fakültesi, nkilinc@kku.edu.tr.

${ }^{2}$ Kırıkkale Üniversitesi, İktisadi ve İdari Bilimler Fakültesi, efecankilinc@kku.edu.tr.

Atıf için (to cite): Şahbaz Kılınç, N. ve Kılınç, E. C. (2020) Türkiye'de banka kredi kanalının etkinliği. Afyon Kocatepe Üniversitesi Sosyal Bilimler Dergisi, 22(2), 418-431. 


\section{Giriş}

Para otoritelerinin yürütmüş olduğu para politikalarının reel ekonomi üzerindeki etkilerini yansıtan parasal aktarım mekanizmasında kredi kanalı, banka kredileri ve bilanço büyüklükleri üzerinden ele alınmaktadır.

Para politikaları bankacılık sisteminin kredi mekanizmasını doğrudan etkileyebilmektedir. Kredi kanalı hem genişletici hem de daraltıcı para politikası uygulandığında önemli sonuçlar doğurabilmektedir. Daraltıcı para politikası uygulandığında kredi kanallarının etkileri üç sebepten ötürü büyük önem arz etmektedir. Birincisi, kredi kanalı firmaların kredi hacmini, harcama limitlerini ve istihdam kararlarını etkileyebilmektedir. İkincisi, büyük firmalardan daha yüksek kredi kısıtlama riskiyle karşı karşıya olan küçük firmalar, daraltıcı para politikasından daha olumsuz etkilenmektedir. Son olarak, daraltıcı para politikası uygulandığında, kredi piyasalarındaki oluşabilecek eksiklikler nedeniyle, kredi kanalı analizinin temelini oluşturan yanlış bilgi sorunu ortaya çıkabilmektedir (Mishkin, 2000, s. 289).

Mishkin (1995) geleneksel parasal aktarım kanallarını; faiz oran1, döviz kuru, varlık fiyatları ve kredi kanalı şeklinde tasnif etmiştir Bazı çalışmalarda, bu sınıflandırma parasal görüş ve kredi görüşü olarak yapılmıştır (Cecchetti, 1999, s. 13; Bernanke, 1988, s. 3-11, Bernanke, 1993, s. 55-57). Kredi görüşünde parasal aktarım sürecinde bankalar aktif rol oynamaktadır. Buna göre daraltıcı para politikasından sonra bankaların özel sektöre kullandırdığ 1 krediler azalmakta, banka kredilerindeki düşüş şirketlerin yatırımlarında düşüşe neden olmaktadır. Öte yandan, genişletici para politikası uygulandığında banka kredileri artmakta, firmaların yatırımları da buna paralel olarak yükselmektedir.

Bu çalışmada, Türkiye'de banka kredi kanalının etkinliği incelenmiştir. Bu kapsamda öncelikli olarak parasal aktarım mekanizmaları teorik zeminde tartışılmış, ardından banka kredi kanalı üzerinden analizler yapılmıştır. Analiz bulguları dördüncü bölümde sunulmuş ve makale sonuç ve değerlendirme kısmı ile tamamlanmıştır.

\section{Parasal Aktarım Mekanizması}

Parasal aktarım mekanizması, para otoritesi tarafindan uygulanan para politikalarının reel sektöre ulaştırılmasını sağlamaktadır. Bu mekanizma Şekil 1'de görüldüğü gibi şematize edilebilir. Kuttner ve Mosser (2002)'e göre, parasal aktarım mekanizması birçok kanal yoluyla çalıştığı için karmaşık bir yapıdadır. Açık piyasa işlemlerinin uygulanması sonucunda para politikası değişiklikleri başlamaktadır. Para politikası değişklikleri reel ekonomiye aktarılırken; faiz oranı kanalı, servet kanalı, banka kredi kanalı, döviz kuru kanalı ve parasal kanallardan geçmektedir. Örneğin, açı piyasa alımı neticinde bankacılık sisteminin rezervleri ve buna bağlı olarak kredi arzları artmakta, bu süreç dar kredi kanalı üzerinden toplam talebe ulaşmaktadır. 
Şekil 1. Parasal aktarım mekanizması



Kaynak: Kuttner ve Mosser, 2002, s. 16.

Ekonomik literatürde parasal aktarım mekanizmaları ile ilgili geniş çapta kabul gören iki teori vardır: Keynesyen ve Monetarist Aktarım Mekanizmaları.

Keynesyen Aktarım Mekanizmasl: Keynesyen Likidite Tercihi Teorisine göre, likidite tuzağı hariç, faiz oranları para arzındaki değişime duyarlılık göstermektedir. Faiz Oranlarında meydana gelecek düşüş, yatırımlanı etkileyecek ve gelir seviyesinin çarpan yoluyla artmasına neden olacaktır (Altunoz, 2010, s. 62; Laidler, 1982, s. 112). Likidite tuzağ 1 durumunda ise para talebinin faiz esnekliğinin sonsuz olmasıyla (yani paranın atıl bir biçimde elde tutulmasıyla) para arzında meydana gelecek artış faiz oranlarında düşüşe neden olmayacaktır.

Monetarist Aktarım Mekanizmast: Parasalcı aktarım mekanizması, miktar teorisiyle açıklanmaktadır. Monetaristlere göre para stoku dışsaldır ve sadece para otoritesinin davranışına bağlıdır. Para, nominal harcamaları doğrudan etkiler. Kısa dönemde, eğer ekonomi tam istihdam seviyesine yakınsa, para sadece genel fiyat seviyesini etkiler, ancak istihdamı etkilemez. Ekonomi tam istihdam düzeyinin altındaysa, para stokundaki artış kısa dönemde reel geliri etkileyebilir ancak uzun vadede sadece genel fiyat seviyesini artırır (Friedman, 1987, s. 3-5).

Moneratist parasal aktarım mekanizmasına göre, para arzındaki değişim portföy yatırımlarının bileşimini değişitirerek reel ekonomiyi etkileyebilmektedir. Buna göre, Merkez Bankası'nın açık piyasa alımı sonrasında bireylerin portföylerindeki para miktarı artmaktadır. Finansal varlıklarını satan yatırımcılar eldeki paralarını verimli bir şekilde kullanmak isteyecekler ve finansal varlık satın almak isteyeceklerdir. Finansal varlıklara olan talep artınca fiyatı artacak (faizler düşecek), buna karşın maddi varlıkların nispi fiyatı azalacak, maddi varlıklara yönelim başlayacaktır. Maddi varlıklara olan talebin artması bu defa bu varlıkların fiyatlarını artıracak ve buna bağlı olarak üretim cazip hale gelecektir. Diğer yandan, faizlerin düşmesi yatırım ve tüketim harcamalarının da artmasına neden olacaktır. Ayrıca fiyatlar genel düzeyi de yükselecektir (Paya, 2013, s. 101-103). 
Moneratistlere göre, para arzı ekonomik bozulmaların temel nedeni olduğu için parasal büyüklükler tercih edilirse ekonomik faaliyetler daha iyi düzenlenecektir. Bununla birlikte, Keynesyenler, parasal büyüklüklerin ve para piyasası koşullarının para politikasına bir rehber olarak önemli olduğunu, ancak para piyasası koşullarına daha fazla dikkat edilmesi gerektiğini ifade etmektedirler (Walsh, 1988).

\section{Kredi Kanalı}

Para politikasının kredi kanalı, toplam talep ve çıktı üzerinde doğrudan etki yapmaktadır. Bu kanalın temel dayanak noktası, banka kredilerinin ticari faaliyetler için önemli bir fon kaynağı olmasının yanı sıra, bu kredilerin tam ikamesi olabilecek başka fon kaynaklarının bulunmamasıdır. Bu etki, uygulamada merkez bankalarının ticari bankaların borç verme yeteneğini kısıtlayabilmesi ve diğer finansman kaynaklarından fon temin edemeyen bağımlı işletmelerin bulunması ile açıklanmaktadır. $\mathrm{Bu}$ şartlar altında, bankaların para politikasındaki sıkılaştırma veya genişleme sinyallerinden önce kredi arzını aynı seviyede tutmak için ticari kağıtları hemen azaltamayacakları varsayılmaktadır (Central Bank of Nigeria, 2019a).

Kredi kanalının işletilmesi, ülkenin ekonomik yapısı, finansal sistem ve aktörlerin bilançolarının bileşimi ve finansal varlıkların vade yapısı gibi çeşitli faktörlerden etkilenmektedir. Kronik enflasyonun özellikle faiz ve varlık fiyatları kanallarından parasal aktarım sürecinin etkinliğini azalttığı bilinmektedir. Bunların yanı sıra, artan faiz oranları ve hızlı döviz kuru artışları, bankaların özkaynaklarının önemli ölçüde azalmasına ve bankaların likit kalmayı tercih etmesine neden olmuştur (İnan, 2001, s. 18).

Kredi kanalının bağımsız olarak çalışması için üç koşulu yerine getirmek gerekir: (i) halka sağlanan krediler ve tahviller tam ikame olmamalıdır; (ii) merkez bankası rezerv tutarını değiştirerek kredi arzını etkilemelidir; (iii) Para politikası değiş̧ikliklerinin etkisini ortadan kaldıran fiyat ayarlamaları mümkün olmamalıdır (Telatar, 2002, s. 91).

Parasal aktarım mekanizmasının kredi kanalının açıklanmasında, bilanço kanalı ve banka kredi kanalı olmak üzere iki farklı yaklaşım sözkonusudur (Aslanidi, 2007: 10). Bilanço kanalı, özel birimlerin finansal pozisyonunun para politikasının aktarım mekanizmasında oynadığı rolü açıklamaktadır. Para politikasındaki değişimler sadece piyasa faiz oranlarını değil, aynı zamanda özel ekonomik birimlerin finansal pozisyonunu da etkilediğinden, faiz oranlarındaki değişiklikler banka bilançolarını, nakit takiplerini, şirketlerin ve tüketicilerin net değerini etkilemektedir. $\mathrm{Bu}$ anlamda yüksek faiz oranları, nakit akışının, net değerin ve kredilerin düşmesine, bu gelişmelere bağlı olarak toplam talebin azalmasına yol açmaktadır (Central Bank of Nigeria, 2019b).

Para politikasının, özel (finansal olmayan) sektörün bilançosunun sağlamlığı ve bileşimi ile nakit akışları üzerindeki etkileri, kredi kuruluşlarının bu aracılara borç verme istekliliğinin yanı sıra kredinin verildiği koşulları da etkileyebilir. Bu mekanizma asimetrik bilginin finansal sistemdeki rolünü önplana çıkarmaktadır. Parasal bir daralmanın borçluların net servetinde ve cari gelirinde bir azalmaya yol açtı̆̆ 1 varsayılırsa, borç verme daha riskli hale gelebilecek ve küresel kredi miktarı azalabilecektir. Burada borçlanma riskinin artması ters seçim problem ve ahlaki tehlike ile açıklanmaktadır. Borç verenler, borçluların bilançoları ve gelirlerinin kötüleşme eğiliminde olduğunu fark ederlerse, küresel borç verilebilir fon miktarı düşecektir. Borçluların finansal konumlarının kötüleşmesi nedeniyle kendilerine daha düşük teminat verilebileceğinden, kredi sözleşmeleri imzalanmadan önce daha riskli harcama projelerini üstlenebilirler. Ancak, kredi sözleşmeleri imzalandıktan sonra projenin maliyetinin düşük olması nedeniyle temerrüde düşme olasıllğı ortaya çıkabilecektir (Minguez, 1997, s. 11-12).

Banka kredi kanalında ilk aşamada para politikası uygulanmakta ve banka kredi hacmi değiştirilmekte, ikinci aşamada banka kredisi değişikliğine bağlı olarak toplam talep ve üretim seviyesi değişmektedir (Erdoğan ve Beşballı, 2011, s. 29). Genişletici para politikasının bir 
sonucu olarak, banka rezervleri ve mevduatlar artacağından, bankaların verebileceği kredi miktarı artacaktır. Kredi miktarındaki artış, özellikle küçük ve orta ölçekli işletmelerin yatırım harcamalarının artmasına neden olmaktadır. Kredi kanalı çoğunlukla küçük ve orta ölçekli işletmelerin yatırım harcamalarını etkiler çünkü küçük firmalar finansman ihtiyaçlarını karşılamak için banka kredilerine aşırı derecede bağımlıdır. Büyük firmalar, fon ihtiyaçlarını hisse senedi ve tahvil piyasalarından karşılayabilecek güce sahiptir. Dolayısıyla, kredi kanalıyla para politikasında meydana gelen şokların küçük firmaları daha fazla etkileyebileceği söylenebilir (Örnek, 2009, s. 106).

\section{Literatür}

Banka kredi kanallarını analiz eden çalışmaların bulguları birbirinden farklıdır. Bernanke ve Blinder (1992), 1959-1978 döneminde; banka mevduatı, banka menkul kıymetler stoku, banka kredileri, işsizlik oranı ve fiyatların fed faiz oranındaki değişimlere tepkisini VAR modeli ile incelemişlerdir. Çalışma sonucunda, daraltıcı para politikasının bir sonucu olarak, bankaların menkul kıymet yatırımlarını kredilerden daha hızlı azalttığı görülmüştür. $\mathrm{Bu}$ reaksiyon kredi sözleşmelerinin niteliği ile açıklanmıştır. Buna göre, kredi sözleşmeleri belirli bir dönemi kapsar ve kredinin hızla daralmasını önler. Ayrıca, banka kredisi ve reel aktivitedeki hareketlerin eş zamanlı olduğu gözlenmiştir. Bu bulgular kredi kanalının çalıştığı şeklinde yorumlanmıştır. Bununla birlikte, başlangıçta, menkul kıymetlerdeki daralmanın kredilerdekinden daha fazla olması nedeniyle, bu kanalın işlerliğinin kısmi olduğu ifade edilmiştir.

Kashyap ve Stein (1994), sıkı para politikalarının kredi arzı üzerindeki etkisini incelemişlerdir. Çalışmalarında sıkı para politikalarının küçük ölçekli bankanın kredi arzında herhangi bir değişiklik yaratmadığını, ancak büyük ölçekli bankaların kredi arzını azalttı̆̆ını belirlemişlerdir.

Gündüz (2001), 1986-1998 döneminde banka kredi kanalının rolünü VAR analizi ile incelemiştir. Daraltıcı para politikasının ardından banka kredileri ve menkul kıymetlerin çok hızlı bir şekilde azaldığını gözlemlemiş̧tir. Menkul kıymetlerdeki azalışa kıyasla, parasal aktarım mekanizmasında kredi kanalının rolünün daha sınırlı olduğu belirtilmiştir.

Schmitz (2004), Çek Cumhuriyeti, Estonya, Macaristan, Leetonia, Litvanya, Polonya, Slovakya ve Slovenya'daki 261 bankanın bilançolarındaki verileri kullanarak geçiş ülkelerindeki banka kredi kanalının özelliklerini test etmiştir. Avrupa Birliği ülkelerinde, faiz oranlarındaki $\% 1$ 'lik artış kredi büyümesini \% 1,8 azalttığı görülmüştür. Schmitz, kredi kanalından parasal aktarımı yalnızca banka büyüklüğünün etkilediğini ve banka kapitülasyonunun herhangi bir rolü olmadığını ifade etmiştir.

Ferreira (2007), 1990-2002 döneminde panel veri yöntemini kullanarak Avrupa Para Birliği'ne üye ülkelerde kredi kanalının çalışıp-çalışmadığını test etmiştir. Kredi kanalının akışında banka performansının önemini ortaya koyan Ferreira, kredi kanalının para politikasının temel bir kanalı olduğu sonucuna varmış, bu kanalın çalışmasında banka performanslarının ve stratejilerinin etkili olduğunu vurgulamıştır.

Öztürkler ve Çermikli (2007), Türkiye eknomisinde 1990-2006 döneminde para politikasının kredi miktarı ve kredi arzı ile reel ekonomi arasındaki ilişkiyi VAR modeli ve Granger nedensellik teslerini kullanarak analiz etmişlerdir. Bulgular, para politikası şoklarından reel krediye doğru tek yönlü bir nedensellik olduğunu, bankalararası para piyasası faiz oranlarında pozitif bir şok gerçekleştiğinde reel kredi büyüme oranlarının azaldığını göstermiştir.

Beņkovskis (2008), Letonya ekonomisinde banka kredi kanalının etkinliğini 1998Ç2$2006 C ̧ 4$ dönemi kapsamında analiz etmiş, analizleri sonucunda Letonya'daki bazı bankaların yerel parasal şoklara karşı istatistiksel olarak anlamlı negatif reaksiyona sahip olduklarını 
göstermiştir. Buna karşın, toplam kredi büyümesinin ağırlıklı ortalama reaksiyonunun istatistiksel olarak anlamlı olmadığı görülmüştür.

Gambacorta ve Marquez-Ibanez (2011), seçilmiş 15 ülke özelinde 2007-2010 döneminde 2008 Küresel Finans Krizi'nin para politikasının parasal aktarım mekanizması üzerindeki etkisini bankaların kredi mekanizmaları üzerinden araştırmışlardır. Bankaların iş modellerindeki ve piyasa finansman modellerindeki değişikliklerin krizden önce Avrupa ve ABD'deki parasal aktarım mekanizmasını değiştirdiğini göstermişlerdir.

Özsuca ve Akbostancı (2012), 1988-2009 döneminde bankacılık sektörünün Türkiye'de para politikası aktarımındaki rolünü araştırmışlardır. Banka düzeyindeki verilerden elde edilen bulgulara göre 1988-2009 döneminde para politikası değişikliklerine bankaların tepkilerinde farklılıklar vardır. 1988-2001 dönemi için yapılan analizlerde işlevsel bir banka kredi kanalının olduğunu, 2001 sonrası dönemde ise bu etkinin daha güçlü gerçekleştiğini tespit etmişlerdir. 1988-2001 döneminde işlevsel banka kredi kanalının görülmesinin arkasında kazanç kapasitesi ve varlık kalitesi yatarken, 2002 sonrası dönemde büyüklük, likidite, aktifleştirme, aktif kalitesi ve yönetimsel verimlilik faktörleri bankaların para politikalarına olan tepkilerini büyük ölçüde değiştirmiştir.

Ahtik (2012), Slovenya ekonomisi için banka kredi kanalının varlığını araştırmıştır. Çalışmada, 1993-2007 yılları arasındaki yıllık veriler kullanılmıştır. Çalışmanın temel bulguları, Slovenya'da banka kredi kanalının varlığını büyük ölçüde doğrulamıştır.

Altunöz (2013), Türkiye ekonomisinde banka kredi kanalının etkinliğini kredi tayınlaması üzerinden VAR modeli ve Toda-Yamamoto nedenssellik testleri kullanarak araştırmıştır. Analizleri sonucunda, kredi tayınlamasının Türkiye'de banka kredi kanalının etkinliğini sınırladığını göstermiştir.

Uslu ve Karahan (2016), banka kredisi kanalının Türkiye ekonomisindeki etkinliğini 2002: M01-2014: M12 döneminde VAR modelini kullanarak analiz etmişlerdir. Sonuçlar, banka kredi kanalının Türkiye'deki reel ekonomi üzerinde önemli bir rol oynadığını göstermiştir.

Atgür ve Altay (2018), Türkiye ve Endonezya ülkelerinde banka kredi kanalının etkinliğini Faktör Genişlemeli Vektör Otoregresif (FAVAR) ve VAR modelleri yardımıyla incelemişler, analizleri sonucunda her iki ülkede de banka kredi kanalının kısmen çalıştığını ortaya koymuşlardır.

Serel ve Güvenoğlu (2019), banka kredisi kanalının Türkiye ekonomisindeki etkinliğini VAR modelini kullanarak test etmişlerdir. Bulgular, sanayi üretimi ve mevduat bankalarının kullandırdığı kredilerin TCMB ağırlıklı ortalama fonlama maliyetindeki şoka olumsuz tepki verdiğini göstermiştir.

\section{Veri, Metodoloji ve Bulgular}

\subsection{Veri}

Bu çalışmada, banka kredi kanalının etkinliği Türkiye ekonomisi için 2003Ç1-2018Ç4 dönemi kapsamında Vector Autoregressive (VAR) modeli kullanılarak analiz edilmiştir.

Doğrudan yerli bankalardan finansal olmayan özel sektöre sağlanan kredilerin kullanılması suretiyle, çalışmamızın diğer çalışmalardan farklılaşması amaçlanmıştır. Analizde yer alan değişkenlerin kısa tanımları Tablo 1'deki gibidir. Analizde kullanılan değişkenler; Kısa Vadeli Faiz Oranları (LNINTRATES), Tüketici Enflasyon Oranı (LNINFRATES), M2 Para Arz (LNM2), Finansal Olmayan Özel Sektörün Kredi Hacmi (LNBANKCREDIT), Nominal Efektif Döviz Kuru (LNNER) ve Sanayi Üretim Endeksi (LNINDUSTRY) şeklindedir. Logaritmik forma dönüştürülen seriler, Census-X13 yöntemi kullanılarak mevsimselikten arındırılmıştır. 
Tablo 1. Veri seti

\begin{tabular}{|c|c|}
\hline Değişkenler & Değişkenlerin Tanımları \\
\hline $\begin{array}{l}\text { Tüketici Fiyat Endeksi } \\
\text { (LNINFRATES) }\end{array}$ & $\begin{array}{l}\text { Tüketici Fiyat Oranları (TÜFE), hane halkı tarafından satın alınan tüketici mal ve } \\
\text { hizmetlerinin fiyatlarındaki ortalama değişiklikleri ölçer. }\end{array}$ \\
\hline $\begin{array}{l}\text { Faiz Oranları } \\
\text { (LNINTRATES) }\end{array}$ & $\begin{array}{l}\text { Bankaların rezerv gereksinimlerini karşılamak üzere kullanılan kısa vadeli } \\
\text { (gecelik veya ertesi gün) faiz oranıdır (immediate interest rates, call money, } \\
\text { interbank rate). Michailidou (2016)'da ifade edildiği gibi, bu faiz oranı, piyasadaki } \\
\text { gelişmelere çok hızlı tepki verdiği için seçilmiştir. }\end{array}$ \\
\hline M2 Para Arzi (LNM2) & $\begin{array}{l}\text { M2 para arzı, bankalar dışındaki dolaşımdaki para, merkezi hükümet dışındaki } \\
\text { vadesiz mevduat ve merkezi hükümet dışındaki yerleşik sektörlerin tasarruf ve } \\
\text { döviz mevduatının toplamından oluşur. Seri, GSYH'ye oranlanmıştır. }\end{array}$ \\
\hline $\begin{array}{l}\text { Finansal Olmayan Özel } \\
\text { Sektör Kredileri } \\
\text { (LNBANKCREDIT) }\end{array}$ & $\begin{array}{l}\text { BIS'e göre, "finansal olmayan özel sektör" finansal olmayan şirketleri (hem özel } \\
\text { sermayeli hem de kamu sermayeli), hanehalklarını ve hane halklarına hizmet veren } \\
\text { kar amacı gütmeyen kuruluşları içermektedir. Kredi yerli bankalar tarafından } \\
\text { verilmektedir. Seri, GSYH'ye oranlanmıştır. }\end{array}$ \\
\hline $\begin{array}{l}\text { Nominal Efektif Döviz } \\
\text { Kuru, 2010=100 (LNNER) }\end{array}$ & $\begin{array}{l}\text { Nominal efektif döviz kurları, ikili döviz kurlarının ağırlıklı ortalamalarıdır. Daha } \\
\text { fazla bilgi için lütfen bakınız (Klau ve Fung, 2006). }\end{array}$ \\
\hline $\begin{array}{l}\text { Sanayi Üretim Endeksi, } \\
2015=100 \\
\text { (LNINDUSTRY) }\end{array}$ & $\begin{array}{l}\text { Sanayi üretimi; madencilik ve taşocakçılığı, imalat, elektrik, gaz ve su arzı } \\
\text { alanlarında faaliyet gösteren sanayi kuruluşlarının çıtılarını kapsar. }\end{array}$ \\
\hline
\end{tabular}

Kaynaklar: Bank for International Settlements; Federal Reserve Bank of St. Louis; TCMB;

OECD (Erişim Tarihi: 20.12.2019).

\subsection{Yöntem}

Özgen ve Güloğlu (2004)'na göre, makroekonomik değişkenler arasındaki ilişkilerde ve rassal şokların değişken sistem üzerindeki etkisinin incelenmesinde VAR modelleri kullanılmaktadır.

Çok değişkenli zaman serisi modelleri arasında en yalın olanı $y_{1, t}$ ve $y_{2, t}$ olmak üzere iki bağımlı değişkene sahip iki değişkenli VAR modelidir. Serilerin gelişimi bu değişkenlerin geçmiş değerleri ile açıklanmaktadır. Bu basit modeldeki açıklayıcı değişkenlerin $y_{1, t-1}$ ve $y_{2, t-1}$ olduğu anlamına gelmektedir. Her bir değişkenin gecikmeli değerinin olduğu VAR modeli şu şekilde gösterilebilir (Füss, 2007: 1):

$$
\begin{aligned}
& y_{1, t}=a_{11} y_{1, t-1}+a_{12} y_{2, t-1}+u_{1, t} \\
& y_{2, t}=a_{21} y_{1, t-1}+a_{22} y_{2, t-1}+u_{2, t}
\end{aligned}
$$

Matris notasyonu ile

$$
\begin{aligned}
& y_{t}=A_{1} y_{t-1}+u_{t} \\
& A_{1}=\left(\begin{array}{ll}
a_{11} & a_{12} \\
a_{21} & a_{21}
\end{array}\right)
\end{aligned}
$$

Denklemde $a_{i}{ }^{\prime}$ ler $(k \times k)$ katsayı matrisleri ve $u_{t}\left(u_{1 t}, \ldots, u_{k t}\right)$ gözlenemeyen hata terimidir. Burada genellikle pozitif tanımlanmış kovaryans matrisi $\mathrm{E}\left(u_{t} u_{t}^{\prime}\right)=\sum_{u}$ ile zamanla değişmeyen sıfır ortalama bağımsız beyaz gürültü işlemi olduğu varsayılır. Bir başka ifadeyle, $u_{t}$ 'ler $u_{t} \sim\left(0, \sum_{u}\right)$ ile bağımsız stokastik vektörlerdir (Lütkepohl, 2004, s. 88).

VAR analizinden elde edilen katsayıları yorumlamak oldukça zordur. Denklem 
sistemlerine uygulanacak şoklar olması durumunda, değişkenlerin reaksiyonları "etki-tepki analizi" ile yorumlanabilir. Etki-tepki analizi kullanılarak, ilgili değişkenin ve diğer değişkenlerin modeldeki her bir değişkene verilecek şoklara karşı tepkileri ölçülebilmektedir. (Lütkepohl ve Saikkonen, 1997, s. 127-157).

\subsection{Bulgular}

Etkili ve tutarlı bir VAR analizi için, modeldeki tüm değişkenlerin durağan olması gerekir. Serilerin durağanlığı birim kök testleri kullanılarak belirlenir. Bu çalışmada, serilerin durağanlıklarının belirlenmesinde Genişletilmiş Dickey Fuller (ADF) ve Phillips-Perron (PP) testleri tercih edilmiştir. Tablo 2'de yer alan ilgili birim kök testlerinin sonuçlarına göre tüm değişkenler durağan değildir. Durağan olmayan bu değişkenler birinci farkları alınarak durağan hale getirilmiştir.

Tablo 2. ADF ve PP testleri

\begin{tabular}{|c|c|c|c|c|}
\hline \multicolumn{5}{|c|}{ DÜZEY } \\
\hline Değişkenler/ & \multicolumn{2}{|c|}{ Sabitli } & \multicolumn{2}{|c|}{ Sabitli ve Trendli } \\
\hline Birim Kök Testi & $\mathrm{ADF}$ & PP & $\mathrm{ADF}$ & PP \\
\hline & t stat & t stat & t stat & t stat \\
\hline LNINFRATES & -1.198849 & $-2.830945^{*}$ & -0.923980 & -2.375045 \\
\hline LNM2 & $-12.24287 * * *$ & $-3.002970 * * *$ & -1.755433 & -1.755433 \\
\hline LNBANKCREDIT & $-3.357698 * *$ & $-3.673263 * * *$ & 0.257924 & 1.012212 \\
\hline LNNER & 2.467152 & -0.771761 & 3.886412 & -0.846086 \\
\hline LNINDUSTRY & -1.649178 & -2.547999 & -1.368655 & -2.415435 \\
\hline LNINTRATES & -2.153410 & -2.170362 & -1.319557 & -1.152160 \\
\hline \multicolumn{5}{|c|}{ BİRINCİ FARKLAR } \\
\hline Değișkenler/ & \multicolumn{2}{|c|}{ Sabitli } & \multicolumn{2}{|c|}{ Sabitli ve Trendli } \\
\hline Birim Kök Testi & $\mathrm{ADF}$ & PP & $\mathrm{ADF}$ & PP \\
\hline & t stat & t stat & $\mathrm{t}$ stat & t stat \\
\hline DLNINFRATES & $-7.533144 * * *$ & $-5.959391 * * *$ & $-8.672523 * * *$ & $-6.478877 * * *$ \\
\hline DLNM2 & $-4.022747 * * *$ & $-6.882615 * * *$ & $-7.311713 * * *$ & $-7.309472 * * *$ \\
\hline DLNBANKCREDIT & $-5.659539 * * *$ & $-5.834235 * * *$ & $-5.076775 * * *$ & $-7.701456 * * *$ \\
\hline DLNNER & $-6.836389 * * *$ & $-7.435523^{* * *}$ & $-6.818440 * * *$ & $-7.416996^{* * *}$ \\
\hline DLNINDUSTRY & $-6.851126 * * *$ & $-6.894456^{* * * *}$ & $-6.926000 * * *$ & $-6.965893 * * *$ \\
\hline DLNINTRATES & $-6.112213 * * *$ & $-6.735098 * * *$ & $-6.559817 * * *$ & $-8.771997 * * *$ \\
\hline
\end{tabular}

VAR modeli tahmini yapılmadan uygun gecikme uzunluğunun tespit edilmesi gerekmektedir. Akaike Bilgi Kriteri (AIC) değerlerinin 4 gecikme için minimum değer verdiği ve diğer gecikme kriterlerinin 1 gecikme için minimum değeri sağladığı görülmüştür. Optimum gecikme seviyesi 1 olarak belirlenmiştir (bakınız Tablo 3).

Tablo 3. Gecikme uzunluğu

\begin{tabular}{ccccccc}
\hline Lag & LogL & LR & FPE & AIC & SC & HQ \\
\hline 0 & 606.5241 & NA & $3.52 \mathrm{e}-18$ & -20.32285 & -20.07636 & -20.22663 \\
1 & 744.4606 & $238.4665^{*}$ & $1.75 \mathrm{e}-19^{*}$ & -23.33765 & $-21.36575^{*}$ & $-22.56790^{*}$ \\
2 & 786.6874 & 62.98239 & $2.35 \mathrm{e}-19$ & -23.10805 & -19.41074 & -21.66477 \\
3 & 835.6064 & 61.35602 & $2.84 \mathrm{e}-19$ & -23.10530 & -17.68258 & -20.98849 \\
4 & 892.6752 & 58.03605 & $3.18 \mathrm{e}-19$ & $-23.37882^{*}$ & -16.23068 & -20.58848
\end{tabular}

* kriter tarafından seçilen gecikme sırasını gösterir. LR: Log Olabilirlik, FPE: Son Ongörü Hatası, AIC: Akaike Bilgi Kriteri, SC: Schwarz Bilgi Kriteri, HQ: Hannan-Quinn Bilgi Kriteri.

AR karakteristik polinomunun ters kökleri, VAR modelinin durağan olup olmadığını görmek için incelenmiştir. Şekil 2'ye göz atıldığında, modelin tüm ters köklerinin birim çember içerisinde yer aldığı tespit edilmektedir. Bu nedenle, VAR modelinin istikrarlı olduğu söylenebilir. 
Şekil 2. AR karakteristik polinomun ters kökleri Inverse Roots of AR Characteristic Polynomial

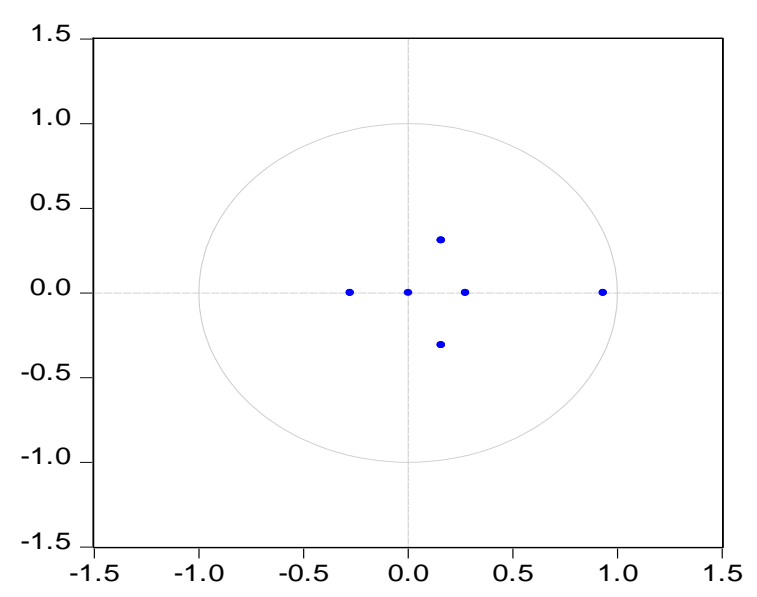

VAR modelinde otokorelasyon problemi olup-olmadığ 1 incelenmiş ve bulgular Tablo 4'te verilmiştir. $\mathrm{LM}$ test sonuçlarına göre $\mathrm{H}_{0}$ hipotezi birinci gecikme düzeyi için reddedilememiştir. Bu nedenle VAR modelinde otokorelasyon sorunu yoktur.

Tablo 4. LM otokorelasyon testi

\begin{tabular}{ccccccc}
\hline Gecikme & LRE* stat & df & Prob. & Rao F-stat & df & Prob. \\
\hline 1 & 43.99439 & 36 & 0.1691 & 1.249093 & $(36,196.0)$ & 0.1721 \\
2 & 35.29855 & 36 & 0.5018 & 0.981326 & $(36,196.0)$ & 0.5056 \\
3 & 62.14757 & 36 & 0.0044 & 1.844583 & $(36,196.0)$ & 0.0046 \\
4 & 48.08586 & 36 & 0.0858 & 1.378912 & $(36,196.0)$ & 0.0878 \\
\hline
\end{tabular}

VAR modelinde hata teriminin varyansının gözlemden gözleme değişip-değişmediği, yani değişen varyans sorununun olup-olmadığı incelenmiştir. Tablo 5'te yer alan sonuçlardan da anlaşılabileceği gibi, modelde değişen varyans sorunu görülmemektedir.

Tablo 5. VAR değişen varyans testi

\begin{tabular}{ccc}
\hline Chi-sq & Df & Prob. \\
\hline 272.6035 & 252 & 0.1779 \\
\hline
\end{tabular}

VAR analizi ile Türkiye'deki banka kredi kanalı mekanizmasının etkinliğini göstermek için etki-tepki fonksiyonları ve varyans ayrıştırmalarının sonuçları sunulmuştur.

Şekil 3'teki ikinci hattın üçüncü panelinde görüldüğü gibi, faiz oranına standart bir sapma şok uygulandığında, sanayi üretim endeksi ekonomik beklentiler doğrultusunda dördüncü çeyreğe kadar negatif tepki göstermiştir. Faiz oranlarının yükselmesi borçlanma araçlarının maliyetini artırmış, bu da özellikle firmalar için yatırım ve üretim faaliyetlerinin bozulmasına neden olmuştur. Finansal olmayan özel sektörün kredi hacminin faiz oranlarındaki şoka tepkisi dördüncü döneme kadar negatif olmuş ve ardından uzun dönem durağan durum dengesine yönelmiştir. 
Şekil 3. Etki-tepki fonksiyonları

Response to Cholesky One S.D. (d.f. adjusted) Innovations \pm 2 S.E.

Response of DLNINTRATES to DLNINTRATES

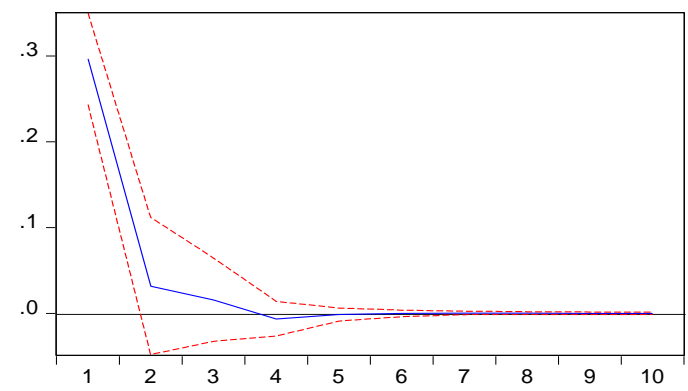

Response of DLNNER to DLNINTRATES

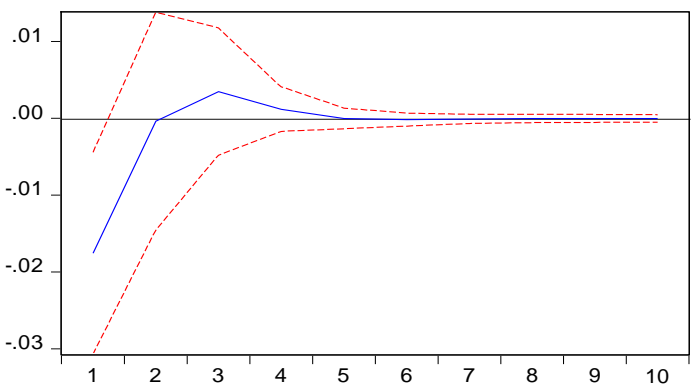

Response of DLNINFRATES to DLNINTRATES

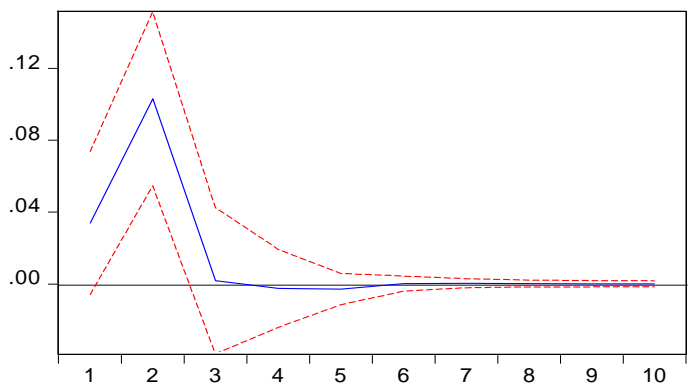

Response of DLNM2 to DLNINTRATES

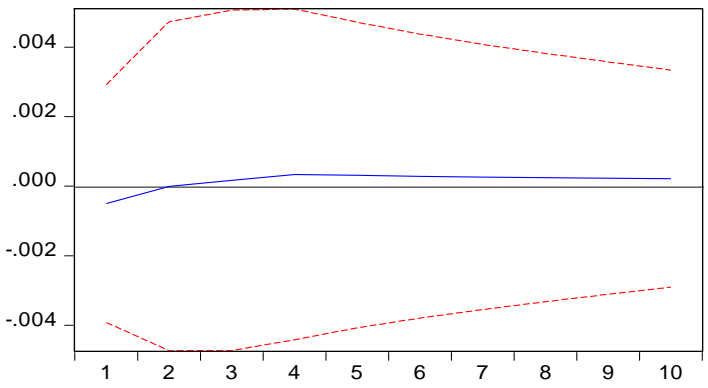

Response of DLNBANKCREDIT to DLNINTRATES

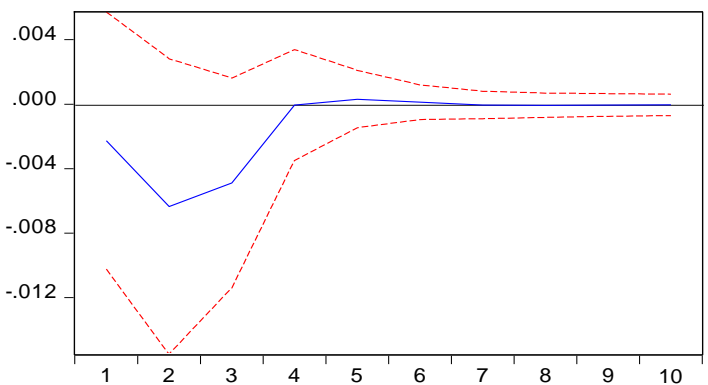

Response of DLNINDUSTRY to DLNINTRATES

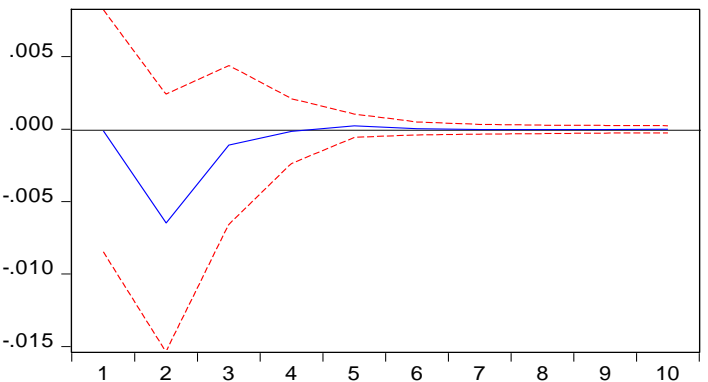

Panelin ilk sütununun üçüncü satırı enflasyon oranının faiz oranına tepkisini yansıtmaktadır. Faiz oranına şok uygulandığında enflasyon oranları ilk dönemde yüksek ve olumlu bir tepki göstermiş, ancak bu tepki ikinci dönemde hızla azalmış ve bu düşüş altıncı döneme kadar devam etmiş, sonra etkisini kaybetmiştir. Bu sonuç, faiz oranlarının enflasyonu düşürücü etkisinin uzun vadede ortaya çıkacağını söyleyen genel ekonomik teori ile uyumludur. Etki-tepki fonksiyonlarından elde edilen sonuçların önemli bir bölümü ekonomik beklentilerle örtüşmektedir. Temel bulgular, Türkiye ekonomisinde banka kredi kanalının çalıştı̆̆ını göstermektedir.

Şekil 4'te yer alan varyans ayrıştırmasının sonuçlarına göre; nominal efektif döviz kuru, özel sektörün kredi hacminin tahmini hata varyansının yaklaşı $\% 17$ 'sini, faiz oranı ve para arz şokları ise yaklaşı \% 5'ini oluşturmuştur. Diğer taraftan, yaklaşı finasal olmayan özel sektör kredi hacminin tahmini hata varyansında sanayi üretim endeksinin payı $\% 1,5$ ve enflasyon oranlarının payı sadece $\% 0,3$ 'tür. 
Şekil 4. Varyans ayrıştırmaları

Variance Decomposition using Cholesky (d.f. adjusted) Factors

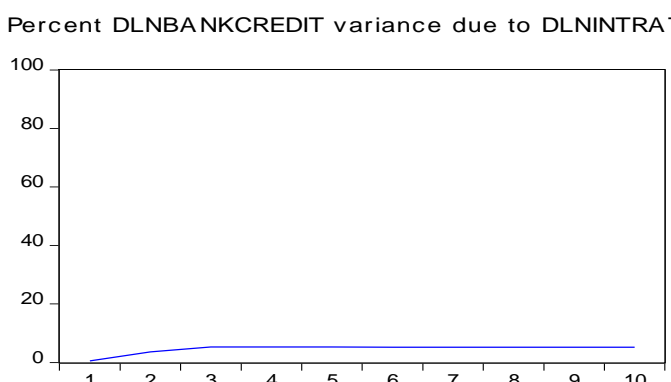

Percent DLNBANKCREDIT variance due to DLNNER

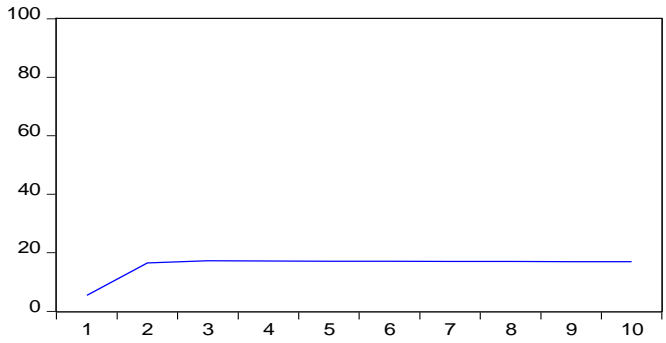

Percent DLNBANKCREDIT variance due to DLNINFRATES 100



Percent DLNBANKCREDIT variance due to DLNM2

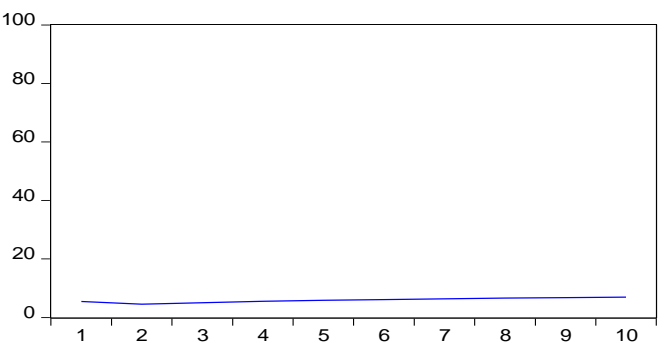

Percent DLNBANKCREDIT variance due to DLNBANKCREDIT

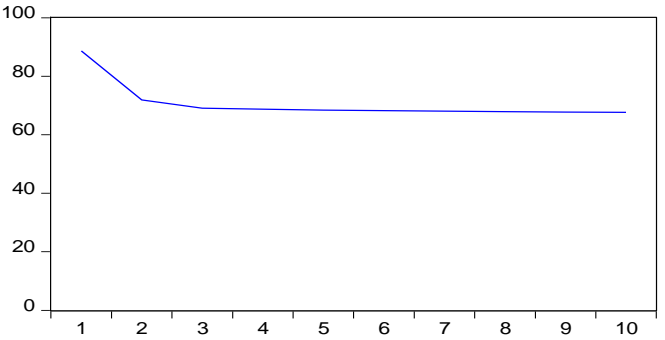

Percent DLNBANKCREDIT variance due to DLNINDUSTRY

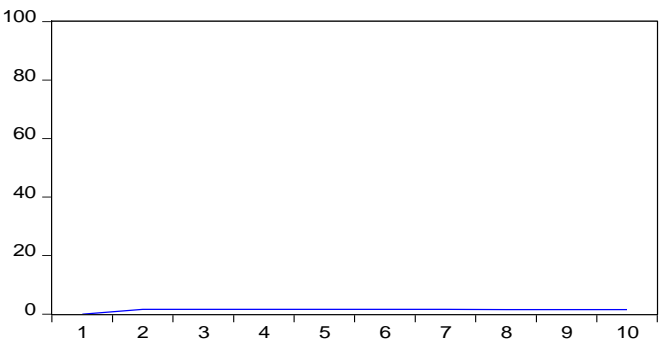

\section{Sonuç ve Değerlendirme}

Merkez Bankası, banka kredilerini etkileyerek piyasaları şekillendirebilir. Özellikle enflasyon dönemlerinde Merkez Bankaları parasal sıkılaştırma uygulayarak banka kredilerini kısıtlamaya çalışmakta ve böylece ekonomiyi yavaşlatmak istemektedir. Türkiye ekonomisi özelinde, Türkiye Cumhuriyet Merkez Bankası (TCMB) gecelik borçlanma faiz oranlarını yükseltmekte, böylece paranın piyasadan çekilmesini sağlamaktadır. Paranın piyasadan çekilmesi ekonominin yavaşlamasına yardımcı olmaktadır. Faiz oranlarındaki bu değişiklik döviz kurlarını ve dolayısıyla fiyatları etkilemektedir. Bu bakımdan, banka kredilerini etkileyen değişkenlerin (faiz oranı, enflasyon, döviz kuru, sanayi üretim endeksi vb.) incelenmesi ve banka kredi kanalının etkin bir şekilde çalışıp çalışmadığının analiz edilmesi önemli bir konudur.

2000 ve 2001 krizlerinden sonra Türk bankacılık sistemi, TCMB ve Bankacılık Düzenleme ve Denetleme Kurumu (BDDK) tarafından belirlenen çeşitli politikalar ile yeniden yapılanma sürecine girmiştir. Türkiye'deki bu bankacılık krizleri ve 2008 Küresel Finansal Kriz, bankacılık sektörünün istikrarının ve iş sektörüne kredi sağlamadaki rolünün önemini vurgulamıştır. Parasal aktarım mekanizmasında kredi kanalı, banka kredi kanalı ve bilanço kanalı aracılığıyla önemli bir rol oynamaktadır. Kredi kanalı mekanizması, bir ekonominin, merkez bankasının faaliyetlerine firmalara ve tüketicilere sağladığı kredi hacmine ilişkin para politikasından nasıl etkilendiğini ifade etmektedir. 
Bu çalışmada, 2003Ç1- 2018Ç4 dönemi verileri kullanılarak, banka kredi kanalının Türkiye'deki etkinliği VAR modeli ile incelenmiştir. VAR tahminlerinden elde edilen etki-tepki fonksiyonları, faiz oranındaki pozitif bir şokun sanayi üretim endeksi ve finansal olmayan özel sektörün kredi hacmi üzerinde uzun bir süre (dört dönem) negatif bir etkisi olduğunu göstermiştir. Sonuçlar, banka kredi kanalının Türkiye'de çalıştığını ortaya koymuştur.

\section{Kaynakça}

Ahtik, M. (2012). Bank lending channel in Slovenia: panel data analysis. Prague Economics Papers, 1, 50-68, (Erişim tarihi: 11.11.2019).

Altunöz, U. (2010). The monetary transmission mechanism. Bankacllar Dergisi, 73, 54-68.

Altunöz, U. (2013). Türkiye'de banka kredi kanalinin etkinliği üzerine ampirik bir çalışma: kredi tayınlaması. Akademik Bakış Dergisi, 37, 1-20.

Aslanidi, O. (2007). The optimal monetary policy and the channels of monetary transmission mechanism in CIS-7 countries: the case of Georgia. CERGE-EI Discussion Paper, 12

Atgür, M. ve Altay, N. O. (2018). Yeni para politikası arayışları bağlamında parasal aktarım mekanizması faiz kanalının işleyişi: Türkiye ve Endonezya ülke örnekleri. Uluslararası Yönetim İktisat ve İsletme Dergisi, 14(3), 601-624.

Bank for International Settlements (2019), http://stats.bis.org/statx/toc/LBS.html2 (Erişim tarihi: 20.12.2019).

Benkovskis, K. (2008). Is there a bank lending channel of monetary policy in Latvia? evidence from bank level data (No. 2008/01).

Bernanke, B. (1988). Monetary policy transmission: through money or credit?. Federal Reserve Bank of Philadelphia Business Review, November/December, 3-11.

Bernanke, B. ve Blinder, A. S. (1992). The federal funds rate and the channels of monetary policy. American Economic Review, 82(4), 901-921.

Bernanke, B. (1993). Credit in the macroeconomy, Federal Reserve Bank of Newyork Quarterly Review, 18(1), 50-70.

Cecchetti, S. G. (1999). Legal structure, financial structure and the monetary policy transmission mechanism. FRBNY Economic Policy Review, July, 9-28.

Central Bank of Nigeria (2019a). https:/www.cbn.gov.ng/Out/EduSeries/Series14.pdf (Erişim tarihi: 01.12.2019).

Central Bank of Nigeria (2019b). https://www.cbn.gov.ng/Out/EduSeries/Series15.pdf (Erişim tarihi: 01.12.2019).

Erdoğan, S., ve Beşballi, S. G. (2011). Türkiye'de banka kredileri kanalının işleyişi üzerine ampirik bir analiz. Doğuş Üniversitesi Dergisi, 11(1), 28-41.

Federal Reserve Bank of St. Louis (2019), https://research.stlouisfed.org/ (Erişim tarihi: 20.12.2019).

Ferreira, C. (2007). The bank lending channel transmission of monetary policy in the EMU: A case study of Portugal. The European Journal of Finance, 13(2), 181-193.

Friedman, M. (1987). The quantity theory of money. J. Eatwell, M. Milgate ve P. Newman (Ed), The new palgrave: A dictionary of economics içinde (ss. 1-40), London: MacMillan.

Füss, R., (2007), Vector autoregressive models, financial data analysis, Department of Empirical Research and Econometrics. 
Gambacorta, L. ve Ibanes M. D. (2011). The bank lending channel lessons from the crisis. European Central Bank Working Paper Series, No 1335/May 2011.

Gündüz, L. (2001). Türkiye'de parasal aktarim mekanizması ve banka kredi kanalı. IMKB Dergisi, 5(18), 13-30.

İnan, E. A. (2001). Parasal aktarım mekanizmasının kredi kanalı ve Türkiye. Bankacılar Dergisi, 39, 3-19.

Kashyap A. K. ve Stein J. C. (1994). The impact of monetary policy on bank balance sheets. NBER Working Papers, No 4821, 1-63.

Klau, M. ve Fung, S. S. (2006). The new BIS effective exchange rate indices, BIS Quarterly Review, 51-65.

Laidler, D. (1982). Monetarist perspective. Oxford: Phillip Alan.

Lütkepohl, H. ve Saikkonen, P. (1997). Impulse response analysis in infinite order cointegrated vector autoregressive processes. Journal of Econometrics, 81(1),127-157.

Lütkepohl, H. (2004). Vector autoregressive and vector error correction models, M. Krätzig ve H. Lütkepohl (Ed), Applied time series econometrics içinde (ss.86-158). Cambridge/MA: Cambridge University Press.

Michailidou, D. M. (2016). The inexorable evolution of financialisation: financial crises in emerging markets. Hampshire: Palgrave Macmillan.

Mínguez, J. M. G. (1997). The balance-sheet transmission channel of monetary policy: the cases of Germany and Spain. Banco de Espana, Servicio de Estudios, Documento de Trabajo nQ 9713.

Mishkin, F. S. (1995). Symposium on the monetary transmission mechanism. Journal of Economic Perspectives, 9(4),3-10.

Mishkin, F. S. (2000). Para teorisi ve politikası. İstanbul: Bilim Teknik Yayınevi.

OECD (2019), http://stats.oecd.org/ (Erişim Tarihi: 20.12.2019).

Örnek, İ. (2009). Türkiye'de parasal aktarım mekanizması kanallarının işleyişi. Maliye Dergisi, $156,104-125$

Özsuca, A. E. ve Akbostanc1, E. (2012). An empirical analysis of the bank lending channel in Turkey. Economic Research Center Middle East Technical University ERC Working Papers in Economics 12/05.

Özgen, B. F. ve Güloğlu, B. (2004). Economic effects of domestic debt VAR analysis technique in Turkey. METU Studies in Development, 31, 93-114.

Öztürkler, H. ve Çermikli, A. H. (2007). Türkiye'de bir parasal aktarım kanalı olarak banka kredileri. Finans Politik \& Ekonomik Yorumlar, 44(514), 57-68.

Paya, M. (2013). Para teorisi ve politikast. İstanbul: Türkmen Kitabevi.

Petursson, T. G. (2001). The transmission mechanism of monetary policy. Monetary Bulletin, 4, 2-77.

Schmitz, B. (2004). What role do banks play in monetary policy transmission in EU accession countries? National Bank of Hungary. 3rd Macroeconomic Policy Research Workshop, 2930 October.

Serel, A. ve Güvenoğlu, H. (2019). Banka kredi kanalının işleyişi: Türkiye uygulaması. Business and Economics Research Journal, 10(4), 867-883.

TCMB (2019), https://evds2.tcmb.gov.tr/ (Erişim Tarihi: 20.12.2019). 
Telatar, E. (2002). Fiyat istikrari nedir? ne? nasıl? kimin için?. Ankara: Imaj Yayınevi.

Uslu, N. C. ve Karahan, P. (2016). An analysis on the efficiency of bank lending channel in Turkey. Journal of Business Economics and Finance, 5(2), 206-217.

Walsh C. (1998). Monetary Theory and Policy, MIT Press. http://www.strongnet.org/cms/lib6/OH01000884/Centricity/Domain/301/3040_s76.pdf (Erişim tarihi: 15.11.2019).

ETIKK ve BİLIMSEL İLKELER SORUMLULUK BEYANI

$\mathrm{Bu}$ çalışmanın tüm hazırlanma süreçlerinde etik kurallara ve bilimsel atıf gösterme ilkelerine riayet edildiğini yazar(lar) beyan eder. Aksi bir durumun tespiti halinde Afyon Kocatepe Üniversitesi Sosyal Bilimler Dergisi'nin hiçbir sorumluluğu olmayıp, tüm sorumluluk makale yazarlarına aittir. 